\title{
Karacabey'de (Bursa) Doğal Yayılış Yapan Gümüşi Ihlamur (Tilia tomentosa Moench.)'un Bazi Morfolojik Özellikleri ile Yaprak ve Çiçek Uçucu Bileșenlerinin Belirlenmesi
}

\author{
Ayşe Gül Sarıkaya ${ }^{1 *}$, Sefa Doğdu² \\ 1* Bursa Teknik Üniversitesi, Orman Fakültesi, Orman Mühendisliği Bölümü, Bursa, Türkiye, (ORCID: 0000-0002-0641-4445), aysegul.sarikaya@ btu.edu.tr

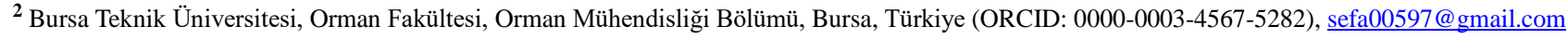

(İlk Geliş Tarihi 19 Ağustos 2020 ve Kabul Tarihi 8 Ocak 2021)

(DOI: $10.31590 /$ ejosat.782403)

\begin{abstract}
ATIF/REFERENCE: Sarıkaya, A. G., Doğdu, S. (2021). Karacabey'de (Bursa) Doğal Yayılış Yapan Gümüşi Ihlamur (Tilia tomentosa Moench.)'un Bazı Morfolojik Özellikleri ile Yaprak ve Çiçek Uçucu Bileşenlerinin Belirlenmesi. Avrupa Bilim ve Teknoloji Dergisi, (21), 17-24.
\end{abstract}

$\ddot{O} z$

Bu çalışma ile Bursa Karacabey'de doğal yayılış yapan ve ekonomik açıdan değerli olan Tilia tomentosa Moench. (Gümüşi Ihlamur)'nın morfolojik özellikleri, uçucu bileşenleri, oranları ve molekülleri belirlenmesi amaçlanmıştır. Yapılan morfolojik ölçüm sonuçlarına göre Gümüşi ıhlamurun yaprakları 36,66-132,12 mm uzunluk ve 39,23-113,92 mm genişlikte, yaprak sapı ise 20,03-69,34 mm uzunluğunda, simoz çiçek kurulu 4-13 çiçekli, brakteleri ise 40,34-109,5 mm uzunluk ve 5,82-21,83 mm genişlikte olduğu tespit edilmiştir. Gaz kromatografisi/kütle spektrometresi (GC-MS) ile kombine edilmiş Tepe Boşluğu- Katı Faz Mikro Ekstraksiyon (HSSPME) tekniği ile çiçek, brakte ve yaprakların floral koku bileşenleri tespit edilmiştir. SPME analiz yöntemi ile çiçek, brakte ve yapraklarında 42 farklı bileşen belirlenmiş olup, n-Hexanal (\%19,35), (E)-2-Hexenal (\%18,45), 2,4 Heptadienal $(\% 14,30)$ ve Limonene $(\% 12,46)$ oranlarıyla ana bileşenler olarak belirlenmiştir. Uçucu bileşen sınıflarına bakıldığında aromatik alkollerin yüksek oranda olduğu bulunmuştur. Ihlamurlar geçmişten günümüze birçok alanda değerlendirilmektedir. Ihlamurun sağlik açısından olumlu etkileri olduğundan günümüzde ıhlamura olan ilgi de artmışır. Ihlamur ile ilgili kapsamlı bilimsel çalışmaların arttırılması önerilmektedir.

Anahtar Kelimeler: Tilia tomentosa (Gümüşi Ihlamur), Bursa-Karacabey, morfolojik özellikler, SPME, Uçucu bileşen.

\section{Determination to Some Morphological Characteristics and Leaf and Flower Volatile Components of Silver Linden (Tilia tomentosa Moench.) Distributed in Karacabey (Bursa)}

\begin{abstract}
In this study, it was aimed to determine the morphological characteristics, volatile components, ratios and molecules of Tilia tomentosa Moench. (Silver Lime), which is naturally spreading in Bursa Karacabey and is economically valuable. According to the results of the morphological measurements, the leaves of the silver linden are 36,66-132,12 mm in length and 39,23-113,.92 $\mathrm{mm}$ in width, the petiole is $20,03-69,34 \mathrm{~mm}$ long, the symosis flower board with 4-13 flowers, braces 40,34-109,5 mm in length and 5,82$21,83 \mathrm{~mm}$ in width. Floral fragrance components of flowers, brackets and leaves were determined by the Head Space-Solid Phase Micro Extraction (HS-SPME) technique combined with gas chromatography / mass spectrometry (GC-MS). 42 different components were determined in flower, brachte and leaves, n-Hexanal (19,35\%), (E) -2-Hexenal (18,45\%), 2,4 Heptadienal (14,30\%) and Limonene $(12,46 \%)$ as the main components with the SPME analysis method. It was found that aromatic alcohols were high. Linden is used in many areas from past to present. Since linden has positive health effects, interest in linden has increased today. It is suggested to increase comprehensive scientific studies on linden.
\end{abstract}

Keywords: Tilia tomentosa (Silver linden), Bursa-Karacabey, morphological characteristics, SPME, Volatile component.

*Sorumlu Yazar: aysegul.sarikaya@btu.edu.tr 


\section{Giriş}

Güney Avrupa ile Güneybatı Asya floraları arasında yer almasından dolayı tür çeşitliliği ve endemizmin yüksek olduğu bir konumda yer alan Türkiye'de, doğal olarak yetişen 11.466 bitki taksonu bulunmakta ve bu bitki taksonlarınında yaklaşık 3649 tanesi endemiktir (Tan, 1992; Güner, 2012). T1bbi bitkilerin tarihinin insanlık tarihi kadar eski olduğu bilinmektedir (Başer, 2008). Bitkilerle tedavi yolu çok eski yıllardan günümüze kadar dayanmaktadır. Türk tarihinde de Lokman Hekim ile ilgili yazılar ve hatta mitolojik ölüme çare bulduğu inanışı insanların doğal bitkilere ve bu bitkilerden yapılan ilaçlara olan ilgisini arttırmıştır (Erdemir, 1998).

Bir çok alanda kullanım alanı bulan tıbbi ve aromatik bitkiler biyolojik kültürel ve endüstriyel kaynaklardır. Tıbbi ve aromatik bitkiler hastalıkların önlenmesi ve sağlık için ilaç olarak geleneksel ve modern tıpta kullanılmaktadır. Aynı zamanda besin takviyeleri, bitkisel çay, baharat olarak beslenmede yararlanılmaktadır. Parfüm ve vücut bakım ürünleri olarak parfümeri ve kozmetikte değerlendirilmesinin yanısıra, parlatıcılar hatta böcek ilaçları olarak sanayinin farklı alanlarındada faydalanılmaktadır. Bu doğal kaynaklara olan talep son yıllarda oldukça artmış ve artmaya devam etmektedir (BAKA, 2012). Dünyanın birçok bölgesinde çeşitli bitkilerin iyileştirici özelliklerinden faydalanmak ve hoşa giden lezzetlerini hissetmek amacıyla çayı içilmektedir. Bitkisel çaylar, tüketim miktarları dikkate alındığında besin unsurlarınca zengin bir kaynak değildir. Bitkilerle tedavi, son yıllara kadar geleneksel olarak devam etmiştir. Bitkisel çay üretiminin bilimsel temellere göre yapılmasıyla bitkisel çay tüketiminde artış gözlenmektedir. Ülke genelinde birkaç özel işletme bitkisel çay üretimi ve dağıtımına başlamıştır. Üretimde en yaygın olan bitkiler kuşburnu, adaçayı, ıhlamur, nane, papatya, tarçın, karanfil, rezene ile bunların ikili veya çoklu kombinasyonlarıdır (Akgül ve Ünver 2001).

Özellikle kış aylarında soğuk algınlığı için ıhlamur en çok tercih edilen bitkilerden birisidir. Ihlamur ağacının çiçekleri Ortaçağ'dan bu yana geleneksel olarak terlemeyi sağlayarak ve ateş düşürmek amacıyla kullanılmaktadır. Geçmişten günümüze kadar idrar söktürücü, spazm çözücü, mideyi sakinleştirici, öksürük ve boğaz ağrılarına karşı, balgam söktürücü, migren ağrılarına karşı, karaciğer ve safra hastalıklarına karşı yararlanıldığı bilinmektedir. Almanya'da resmi olarak şifalı bitki kabul edilen ıhlamur, doktorlar tarafından soğuk algınlığına karsı önerilmektedir. Bazı kültürlerde sadece ıhlamur ağacı altında oturarak epilepsinin tedavi edilebileceğine inanılmaktadır. Ihlamur çayı ülkemizde olduğu gibi farklı kültürlerde geleneksel olarak grip nedeniyle yükselen ateşi düşürmek için içilmektedir. Ihlamur çayının buharı burun tıkanıklığını açmaya yararken, sıcak çayı boğaz ağrısını, öksürüğü iyileştirmektedir. Diğer bir kullanımı ise sinirleri yatıştırmak için sakinleştirici etkisidir. Yatıştırıcı etkisi bulunan ıhlamur çayı gerginliği alır, stresi azaltır ve uykuya geçişi kolaylaştırır. Doğada doğal olarak yetişen Ihlamur ağacının temmuz ve ağustos aylarında toplanan yaprakları ve çiçekleri kurutularak saklanmaktadır (URL-1, 2018).

Odunsu türlerin içinde önemli yere sahip olan ıhlamur türleri (Tilia spp.) çoğunluğu ağaç, bazen de boylu çalı halinde kışın yaprağını döken odunsu bitkilerdir (Tuttu vd., 2017). Tepe kısmı seyrek, geniş ve yuvarlak şeklindedir. Uzun saplı yapraklarının ayası yürek biçiminde ve çarpık, yaprak kenarları e-ISSN: 2148-2683 genellikle dişli nadiren tamdır. Sade veya yıldız tüylü olan yapraklarının dizilişleri almaçlıdır. Çiçekleri en az üçü bir arada olmak üzere sarkan kurullar oluştururlar. Çiçek kurullarının ortak ekseninde bulunan brakte uzun bir kanat şeklindedir. Çiçekleri 5 taç ve 5 çanak yapraktan oluşmuş, sarımsı renkli ve kendine özgü kokuludur. Meyve küremsi, deri gibi sert veya odunsu yapıda olan kapalı meyvedir. Meyve yuvarlakça, odunlaşmış, sert kabuklu olup kabuk üzerinde 4-5 tane, uzunca çıkıntı bulunur. Tohum koyu boz kahverenginde, yumurta biçiminde, çenekler el görünüşünde, uzunca ve sivri dilimlere ayrılmıştır (URL-1, 2018).

Ülkemizde 4 türle temsil edilen hhlamurun (Tilia rubra subsp. caucasica, Tilia cordata, Tilia platyphyllos, Tilia tomentosa) en yaygın olanı ve en çok tanınanı Tilia tomentosa (Synonim:argentea)'dır. Davis (1967)'e göre Tilia argentea olarak isimlendirilen tür Güner (2012) tarafindan dünya literatürü ile uyumluluk sağlaması açısından, tekrar Tilia tomentosa olarak isimlendirilmiştir. Ihlamurlar, gençlikte yavaş büyümelerine rağmen ileriki yaşlarda büyümeleri hızlanmaktadır. Ihlamurlar (özellikle Tilia tomentosa ve Tilia platyphyllos) sicak dağlık vadilerde ve benzeri uygun yetişme ortamlarında geniş çap ve uzun boy yapabilmektedirler. Toprak istekleri orta derecede kabul edilse de en iyi gelişmeyi gevşek, bir ölçüde nemli ve besin maddelerince zengin derin topraklarda yapmaktadır. Kütük ve kök sürgünü verme yeteneği kuvvetlidir. Baltalık ve korulu baltalıklar için elverişli bir ağaç türüdür (Saatçioğlu, 1976; Pigott, 2012). Avrupa-Sibirya elementi olan Tilia tomentosa (Gümüşi Ihlamur) ağırlıklı olarak Batı Karadeniz'de yayılış yapmaktadır. Trakya'da Istranca Dağlarından başlayan bu tür doğuda Zonguldak ve Karabük illerinde, güneyde ise Çanakkale ve Bursa illerinde de doğal yayılış yapmaktadır. Ancak lokal olarak Kuşadası Dilek Yarımadasında ve Hatay'da bulunduğu görülmektedir (Davis, 1967).

Zengin bir biyolojik çeşitliliğe sahip olan Bursa Orman Bölge Müdürlüğü ormanlarında 10.139 ha'lık bir alan Tilia tomentosa (Gümüşi Ihlamur)'nın doğal yetişme alanıdır (Bursa Plan Proje Şube Müdürlüğü, 2017). Çalışmanın konusunu oluşturan Tilia tomentosa (Gümüşi Ihlamur) ülkemizde çok geniş bir yayılış göstermektedir. Sarımsı veya beyazımsı çiçeklerinden dolayı süs bitkisi olarak yetiştirilen gümüşi ıhlamur ağacının boyu 15 - 40 m, yaprakların alt yüzü gümüşi beyaz, yıldız tüylü ve çiçekleri; 5 parçalı, sarımsı renkli, hafif baharlı lezzette olup, kendine has özel ve kuvvetli kokuludur (Uslu, 2004).

Uçucu yağlar ve aromatik ekstreler, koku ve tat endüstrileri tarafından parfüm, gıda katkıları, temizlik ürünleri, kozmetikler ve ilaçların içeriğinde, aroma kimyasallarının kaynağı olarak, doğala özdeş ve yarı-sentetik yararlı aroma kimyasallarının sentez başlangıç maddesi olarak değerlendirilmektedirler (Başer, 1998). Günümüzde tıbbi bitkilerin ve bu bitkilere ait uçucu yağların saf ve özellikle ana etken maddelerinin elde edilip değerlendirilmesi hem bilimsel hem de ekonomik yönden oldukça önem taşımaktadır. Uçucu yă ve bileşenlerinin farmakolojik özellikleri de incelenerek tıp, kozmetik ve endüstriyel alanlarda kullanılabilme imkânlarının yararlı olabileceği düşünülmektedir (Kırbağ, 2000).

Uçucu yağlar eski çağlardan günümüze kadar birçok hastalığın tedavisinde kullanılan ilaçlar arasındadır (Kubeczka, 1979). Halk tıbbında kullanılma amaçları dikkate alınarak bu ilaçlar üzerinde yapılan farmakolojik araştırmalar sonucunda 
bazı biyolojik etkileri bilimsel olarak da ortaya konulmuştur (Şarer, 1991; Kıvanç ve Akgül, 1986). Günümüzde tıbbi bitkilerin ve bu bitkilere ait uçucu yağların saf ve özellikle ana etken maddelerinin elde edilip değerlendirilmesi hem bilimsel hem de ekonomik yönden oldukça önem kazanmıştır. Yapılan bilimsel araştırmalar ele alındığında ıhlamur türlerinin uçucu bileşenlerinin tespiti ile ilgili çalışmalar yok denilecek kadar azdir.

Bu çalışma ile Bursa Karacabey'de doğal yayılış yapan ve ekonomik açıdan değerli olan Tilia tomentosa'nın morfolojik özellikleri, uçucu bileşenleri, oranları ve molekülleri belirlenmiştir. Böylece ekonomiye ve orman halk ilişkilerine önemli katkıları bulunan Tilia tomentosa'nın morfolojik özellikleri ve uçucu bileşenleri tespit edilerek tıp, kozmetik ve endüstriyel alanlarda kullanılabilme imkânları ortaya konulmaya çalışılmıştır.

\section{Materyal ve Metot}

\subsection{Materyal}

Bursa Karacabey'de doğal yayılış yapan Gümüşi ıhlamur (Tilia tomentosa Moench.) popülasyonları çalışmanın materyalini oluşturmaktadır. Toplanan bitki örnekleri herbaryum örneği haline getirildikten sonra teşhisleri Bursa Teknik Üniversitesi Orman Fakültesi’nde yapılmıştır.

Gümüşi ihlamurun morfolojik özelliklerinin belirlenmesi için çiçek, yaprak ve brakte incelenerek gerekli ölçümler yapılmıştır. Ayrıca Gümüşi ıhlamurun uçucu bileşenlerin tespiti için yaprakları, çiçekleri ve brakteleri yarı gölgeli bir yerde uygun şartlarda kurutularak paketlenmiş, analiz için hazır hale getirilmiştir.

\subsection{Yöntem}

\subsubsection{Morfolojik Özelliklere Ait Yöntem}

Bursa Karacabey'de doğal yayılış yapan Gümüşi ıhlamur (Tilia tomentosa Moench.) türünün morfolojik özelliklerinin belirlenmesi için vejetatif ve generatif organları basit rastgele örnekleme yöntemi ile toplanmıştır. Toplanan yaprakların en boy ölçümleri, yaprak sapı uzunluğu, brakte eni ve brakte boyu, çiçek sayısı, gibi özellikleri tespit edilmiştir. Bu özelliklerin tespitinde yaprak, çiçek, brakte'den 50'şer adet ölçüm yapılmıştır (Şekil 1.).

\subsubsection{Yaprak ve çiçek floral uçucu bileşenlerinin HS- SPME/GC-MS analizi ile belirlenmesi}

Vejetasyon döneminde Gümüşi ıhlamurun yaprak ve çiçeklerinin olgunlaşma zamanında belirlenen alanlara gidilerek, ağaçlardan yaprak, çiçek ve brakte örnekleri toplanmıştır. Toplanan yaprak, çiçek ve brakte örnekleri ambalajlara konulacak hiç bekletmeden ve güneş 1şı̆̆ına maruz bırakmadan aynı gün içerisinde laboratuvara nakledilmiştir. Toplanan bitki materyalleri sabit ağırlığa gelene kadar oda sıcaklığında $\left(25^{\circ} \mathrm{C}\right)$ kurutulmuştur.

Gaz kromatografisi/kütle spektrometresi (GC-MS) ile kombine edilmiş Tepe Boşluğu- Katı Faz Mikro Ekstraksiyon (HS-SPME) tekniği ile çiçek ve yaprakların floral koku bileşenleri tespit edilmiştir. Katı faz mikroekstraksiyon (SPME, Supelco, Germany) yöntemi kullanılarak, $10 \mathrm{~mL}$ vial içine konulan 2 g çiçek ve yaprak örnekleri 30 dakika boyunca 60
${ }^{\circ} \mathrm{C}$ 'de tutulduktan sonra tepe boşluğundan $75 \mu \mathrm{m}$ inceliğinde Carbokzen/Polidimetilsilokzan (CAR/PDMS) kaplı fused slica fiber ile uçucu bileşenler absorbe edilmiş ve bekletilmeden HSSPME uyumlu GC-MS (Shimadzu 2010 PLUS) cihazının kapiler kolonuna (Restek Rx-5 Sil MS 30 m x 0.25 mm, 0.25 $\mu \mathrm{m})$ enjekte edilmiştir. Fırın sıcaklığ $140^{\circ} \mathrm{C}$ 'de 2 dakika bekledikten sonra dakikada $4^{\circ} \mathrm{C}$ 'lik artışla ulaşılacak şekilde $250^{\circ} \mathrm{C}$ 'ye programlanmıştır. Enjektör ve dedektör sıcaklıkları $250^{\circ} \mathrm{C}$ olarak ayarlanacak ve iyonlaştırma türü olarak EI $(70 \mathrm{eV})$ ve Helyum (1.61 mL/dakika) taşıyıcı gaz olarak kullanılmıştır (Şekil 2). Wiley, Nist, Tutor, FFNSC kütüphanelerinden uçucu bileşenlerinin tanımlanmasında yararlanılmıştır. LRI (Linear Retention Indices) değerleri, bir seri C7-C30 doymuş n-alkan standartları (Sigma-Aldrich Chemical Co. USA) yardımıyla hesaplanmıştır.

\subsection{3. İstatistiksel Değerlendirme}

Çalışmada morfolojik ölçümlere ait verilerin minimum, maksimum ve aritmetik ortalama değerleri Microsoft Office Excel programında hesaplanmıştır. Verilerin standart sapmaları, varyasyonlar1, IBM SPSS Statistics (istatistik program) paket programı kullanılarak gerçekleştirilmiştir. 


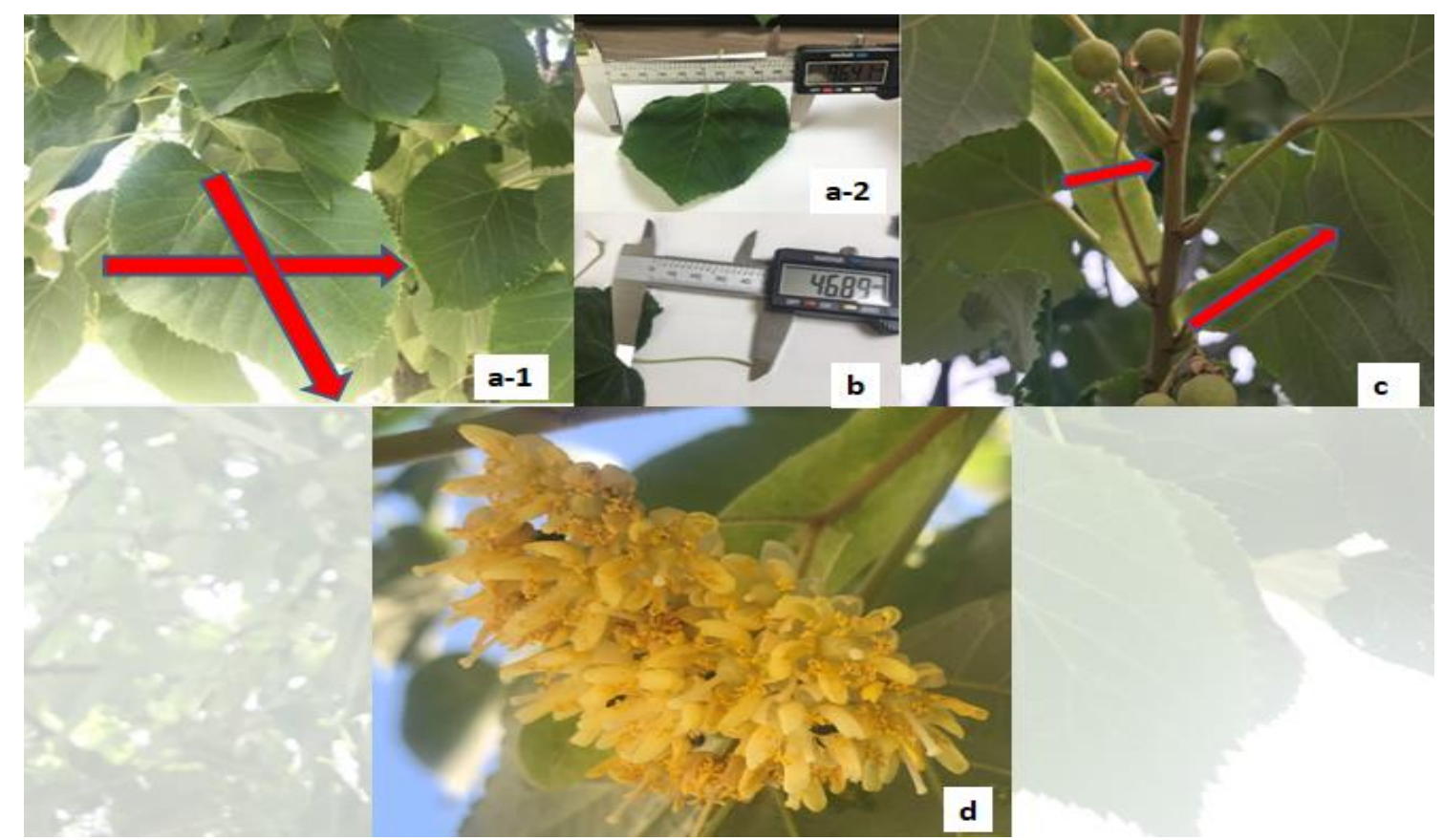

Şekil 1. Morfolojik Ölçümler (a-1 ve a-2:yaprak en-boy, b: yaprak sapı, c: brakte en-boy, d: çiçek)

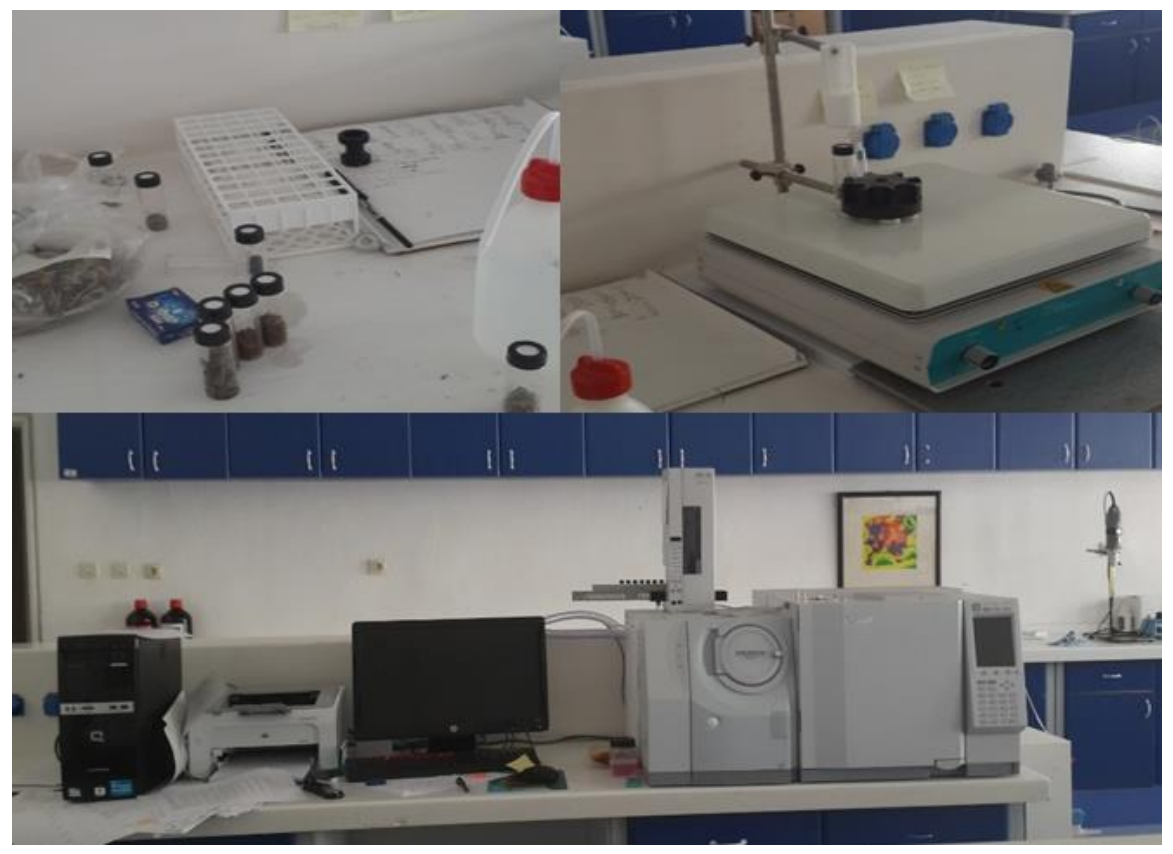

Şekil 2. Yaprak ve Çiçek Uçucu Bileşenlerinin Tespiti

\section{Araştırma Sonuçları ve Tartışma}

\subsection{Morfolojik Özelliklere ve İstatistiksel Değerlendirmeye Ait Bulgular ve Tartışma}

Gümüşi 1hlamur (Tilia tomentosa Moench.) 40 m’ye kadar boylanabilen bir ağaçtır. Gövde ve ana dalların kabuğu açık gri renkli, genç ağaçlarda boyuna yönde düzgün ve sığ oluklu, yaşlandıkça boyuna yönde koyu gri veya siyah çatlaklı yapıdadır. Genç sürgünleri tüylüdür. Tomurcukları 2-3 pulludur; pulların dış kenarları tüylüdür (Browicz, 1968; Toker vd., 1997; Yaltırık ve Efe, 2000; Demir, 2003; Pigott, 2012; Korkusuz, 2014).
Gümüşi 1hlamurun morfolojik özelliklerinin belirlenmesi için çiçek, yaprak ve brakte incelenerek gerekli ölçümler yapıllmış ve Tablo 1'de verilmiştir. Ayrıca çalışmada morfolojik ölçümlere ait verilerin minimum, maksimum ve aritmetik ortalama değerleri Microsoft Office Excel programinda hesaplanmış, verilerin standart sapmaları, varyasyonları, IBM SPSS Statistics (istatistik program) paket programı kullanılarak gerçekleştirilmiş ve sonuçları Tablo 2'de verilmiştir. Gümüşi ıhlamurun geniş yumurta şeklindeki yaprakları 36,66-132,12 mm uzunluk ve 39,23-113,92 mm genişlikte olup aniden sivrilen bir ucu ve testere dişli kenarları vardır. Yaprak yasının üst yüzü tüysüz ve koyu yeşil, alt yüzü ise tamamen beyazımsı yıldız tüylerle kaplıdır. Yaprak sapı ise 20,03-69,34 mm uzunluğunda 
ve tüylüdür. 4-13 çiçekli simoz çiçek kurulu aşağı doğru sarkık çiçekleri Haziran sonu-Temmuz başında açmaktadır. Çiçek ve çiçek kurulu sapları sık ve yumuşak tüylüdür. Çiçekte çok sayıdaki stamenin yanı sıra 5 tane de spatül şeklinde verimsiz stamen bulunur. Brakteleri ise 40,34-109,5 mm uzunluk ve 5,8221,83 mm genişlikte olup tüylüdür. Nuks meyve üzeri az-çok omurgalı, siğilli ve yoğun tüylüdür, kalın bir kabuğa sahiptir.

Tablo 1. Gümüş̧i Ihlamur (Tilia tomentosa Moench.) Türünün Morfolojik Ölçüm Değerleri

\begin{tabular}{|c|c|c|c|c|c|c|c|}
\hline & $\begin{array}{c}\text { Yaprak } \\
\text { Eni }\end{array}$ & $\begin{array}{c}\text { Yaprak } \\
\text { Boyu }\end{array}$ & $\begin{array}{c}\text { Yaprak } \\
\text { Sap } \\
\text { Uzunluğu }\end{array}$ & $\begin{array}{c}\text { Brakte } \\
\text { Eni }\end{array}$ & $\begin{array}{c}\text { Brakte } \\
\text { Boyu }\end{array}$ & $\begin{array}{c}\text { Brakte } \\
\text { Sap } \\
\text { Uzunluğu }\end{array}$ & $\begin{array}{l}\text { Çiçek } \\
\text { Sayısı }\end{array}$ \\
\hline 1. & 57,48 & 77,21 & 34,18 & 10,23 & 48,86 & 18,33 & 8 \\
\hline 2. & 89,22 & 123,67 & 69,34 & 21,83 & 94,86 & 31,64 & 11 \\
\hline 3. & 96,41 & 114,34 & 56,27 & 10,73 & 93,56 & 29,78 & 10 \\
\hline 4. & 72,67 & 77,71 & 38,66 & 7,36 & 56,73 & 16,39 & 8 \\
\hline 5. & 80,4 & 109,92 & 46,89 & 10,73 & 76,2 & 24,55 & 8 \\
\hline 6. & 56,14 & 70,97 & 38,89 & 10,77 & 61,54 & 10,77 & 6 \\
\hline 7. & 76,87 & 100,57 & 54,3 & 15,03 & 57,47 & 14,36 & 8 \\
\hline 8. & 64,07 & 76,12 & 45,27 & 15,05 & 97,83 & 34,31 & 7 \\
\hline 9. & 43,49 & 47,52 & 30,1 & 12,53 & 79,68 & 25,54 & 10 \\
\hline 10. & 39,23 & 36,66 & 21,99 & 8,29 & 74,48 & 23,25 & 11 \\
\hline 11. & 99,12 & 115,94 & 53,87 & 15,92 & 88,47 & 26,25 & 9 \\
\hline 12. & 103,29 & 131,92 & 61,37 & 12,33 & 81,9 & 25,75 & 13 \\
\hline 13. & 82,62 & 110,32 & $\begin{array}{l}51,19 \\
\end{array}$ & 15,99 & 105,64 & 40,71 & 11 \\
\hline 14. & 69,16 & 79,47 & 40,15 & 15,58 & 84,53 & 32,53 & 12 \\
\hline 15. & 44,2 & 51,68 & 32,63 & 13,53 & 86,18 & 34,75 & 8 \\
\hline 16. & 54,6 & 688,44 & 36,38 & 12,72 & 73,8 & 17,98 & 5 \\
\hline 17. & 43,94 & 58,85 & 30,47 & 13,13 & 86,9 & 25,9 & 8 \\
\hline 18. & 69,78 & 91,91 & 46,07 & 15,18 & 96,84 & 33,57 & 12 \\
\hline 19. & 87,91 & 113,54 & 49,15 & 17,97 & 102,52 & 45,62 & 13 \\
\hline 20. & 103,75 & 132,12 & 58 & 19,1 & 101,3 & 23,63 & 9 \\
\hline 21. & 96,32 & 125,19 & 65,56 & 10,36 & 83,14 & 23,11 & 9 \\
\hline 22. & 70,37 & 91,4 & $\begin{array}{l}55,35 \\
\end{array}$ & 13,99 & 91,97 & 38,29 & 13 \\
\hline 23. & 77,52 & 92,02 & 43,84 & 14,34 & 92,66 & 31,38 & 11 \\
\hline 24. & 48,23 & 49,94 & 30,01 & 15,42 & 53,36 & 9,81 & 9 \\
\hline 25. & 93,64 & 123,63 & 56,14 & 12,93 & 85,12 & 28,5 & 11 \\
\hline 26. & 80,27 & 98,28 & 42,18 & 12,92 & 92,68 & 24,84 & 4 \\
\hline 27. & 82,67 & 111,3 & 45,3 & 10,07 & 49,15 & 18,23 & 9 \\
\hline 28. & 104,85 & 129,74 & 50,47 & 12,04 & 94,52 & 42,56 & 11 \\
\hline 29. & 74,87 & 93,31 & 87,19 & 11,37 & 81,51 & 30,87 & 12 \\
\hline 30. & 92,73 & 113,26 & 50 & 8,36 & 48,59 & 20,06 & 9 \\
\hline 31. & 94,65 & 125,18 & $\begin{array}{l}56,03 \\
\end{array}$ & 12,05 & 82,8 & 24,28 & 9 \\
\hline 32. & 102,43 & 110,98 & 61,1 & 6,03 & 47,63 & 11,31 & 7 \\
\hline 33. & 70,37 & 85,87 & 38,25 & 13,48 & 70,72 & 20,33 & 9 \\
\hline 34. & 77,66 & 94,58 & 41,73 & 8,66 & 46 & 18,76 & 9 \\
\hline 35. & 113,92 & 132,12 & 51,22 & 10,12 & 53,46 & 22,84 & 8 \\
\hline 36. & 48,11 & 43,9 & 30,16 & 5,82 & 40,34 & 13,16 & 6 \\
\hline 37. & 58,95 & 86,69 & 66,5 & 17,55 & 109,5 & 43,99 & 11 \\
\hline 38. & 103 & 129,52 & 58,12 & 11,19 & 82,93 & 26,92 & 11 \\
\hline 39. & 83,93 & 91,81 & 40,61 & 9,2 & 72,9 & 33,03 & 8 \\
\hline 40. & 103,09 & 121,88 & 48,39 & 13,01 & 87,23 & 26,9 & 4 \\
\hline 41. & 79,44 & 99,66 & 48,75 & 14,27 & 103,33 & 33,33 & 8 \\
\hline 42. & 67,41 & 75,94 & 37,61 & 12,12 & 79,46 & 26,63 & 9 \\
\hline 43. & 85,16 & 114,04 & 62,91 & 7,95 & 63,59 & 20,97 & 8 \\
\hline 44. & 99,86 & 114,48 & 56,07 & 10,84 & 76,48 & 18,10 & 11 \\
\hline 45. & 101,88 & 124,48 & 50,38 & 16,37 & 83,21 & 34,31 & 12 \\
\hline 46. & 87,18 & 99,07 & 46,13 & 8,14 & 49,23 & 18,08 & 8 \\
\hline 47. & 99,23 & 117,16 & 52,24 & 10,78 & 79,95 & 26,13 & 10 \\
\hline 48. & 79,65 & 106,21 & 57,32 & 14,02 & 88,29 & 31,87 & 11 \\
\hline 49. & 41,63 & 46,93 & 20,03 & 12,75 & 73,4 & 25,59 & 8 \\
\hline 50. & 94,36 & 130,8 & 53,87 & 10,77 & 58,85 & 11,88 & 9 \\
\hline
\end{tabular}


Tablo 2. Gümüşi Ihlamur (Tilia tomentosa Moench.) Türünün Morfolojik Ölçümlerine Ait İstatiksel Değerlendirme

\begin{tabular}{|l|l|l|l|l|l|l|l|}
\hline & $\begin{array}{c}\text { Yaprak } \\
\text { Eni }\end{array}$ & $\begin{array}{c}\text { Yaprak } \\
\text { Boyu }\end{array}$ & $\begin{array}{c}\text { Yaprak } \\
\text { Sap } \\
\text { Uzunluğu }\end{array}$ & $\begin{array}{c}\text { Brakte } \\
\text { Eni }\end{array}$ & $\begin{array}{c}\text { Brakte } \\
\text { Boyu }\end{array}$ & $\begin{array}{c}\text { Brakte } \\
\text { Sap } \\
\text { Uzunluğu }\end{array}$ & \multicolumn{1}{|c|}{$\begin{array}{c}\text { Ççek } \\
\text { Sayısı }\end{array}$} \\
\hline Ölçüm SayıSı & 50 & 50 & 50 & 50 & 50 & 50 & 50 \\
\hline Min. & 39,23 & 36,66 & 20,03 & 5,82 & 40,34 & 9,81 & 4 \\
\hline Max. & 113,92 & 132,12 & 87,19 & 21,83 & 109,5 & 45,62 & 13 \\
\hline Ortalama & 78,9546 & 97,3650 & 47,9726 & 12,4184 & 77,4258 & 25,8334 & 9,22 \\
\hline Std. Sapma & 20,05895 & 26,85244 & 12,68203 & 3,29754 & 18,17089 & 8,69243 & 2,160 \\
\hline
\end{tabular}

Davis (1967)'e göre yaprakları 70-130 mm uzunluk ve 50.5$100 \mathrm{~mm}$ genişlikte, yaprak sapı ise 40.5-60 mm uzunluğunda ve çiçek kurulu 7-10 çiçekli olarak tespit edilmiştir. Yapılan çalışma çalışmamızın sonucundan farklılık göstermektedir.

\subsection{Morfolojik Özelliklere ve İstatistiksel Değerlendirmeye Ait Bulgular ve Tartışma}

Çalışmamızda Bursa Karacabey'de doğal yayılış yapan Gümüşi ihlamurunun (Tilia tomentosa Moench.) çiçeklenme döneminde toplanan çiçek, brakte ve yaprak örneklerinin uçucu yağ bileşenleri SPME (katı faz mikroekstraksiyon yöntemi) analiz yöntemi ile belirlenmiş olup, 42 farklı bileşen tespit edilmiştir. n-Hexanal (\%19,35), (E)-2-Hexenal (\%18,45), 2,4 Heptadienal $(\% 14,30)$ ve Limonene $(\% 12,46)$ oranlariyla ana bileşenler olarak belirlenmiştir. Uçucu bileşen sınıflarına bakıldığında aromatik alkollerin yüksek oranda olduğu bulunmuştur (Çizelge 3).
Gegiu, (2008)'nun Bükreş (Romanya)'ten topladığı Tilia americana, $\mathrm{T}$. tomentosa ve $\mathrm{T}$. platyphillos türlerininin uçucuya bileşenlerini hidrodistilasyon ile belirlemiștir. T. tomentosa'da ana bileşen olarak phytol bileşenini tespit etmiştir. Toker vd., (2011) GC/MS ile Tilia platyphyllos, $T$. rubra ve $T$. tomentosa'nın (Sin.:T. argentea) uçucu yağ bileşenlerini araştırmışlardır. T. tomentosa'da ana bileşen olarak Hexadecanoic acid, 2-phenethyl benzoate, $\beta$-ionone, geranyl acetone, farnesyl acetone ve hexahydrofarnesyl acetone ana bileşenler olarak belirlenmiş̧tir. Fitsiou vd. (2011) Yunanistan ve Romanya'da GC/MS ile T. tomentosa ve T.cordata'nın uçucu yă bileşenlerini belirlemişlerdir. Ana bileşenler olarak $T$. tomentosa'da Linalool $(13.1 \%)$ ve hexahydrofarnesyl acetone (17.7\%) tespit edilmiştir. Yapılan çalışmaların sonuçları bu açılardan çalışmamızdan farklılık göstermektedir.

Tablo 3. Gümüşi Ihlamur (Tilia tomentosa Moench.) Türünün Yaprak ve Çiçek Uçucu Bileşsenleri ve Sinıfları

\begin{tabular}{|c|c|c|c|c|c|}
\hline & R. Time & Bileşenler & $\boldsymbol{\%}$ & Formül & Sinff \\
\hline 1. & 1.628 & Iso Butyraldehyde & 0,69 & $\mathrm{C}_{4} \mathrm{H}_{8} \mathrm{O}$ & AA \\
\hline 2. & 1.755 & 2,3-Butanedione & 3,92 & $\mathrm{C}_{4} \mathrm{H}_{6} \mathrm{O}_{2}$ & AAI \\
\hline 3. & 1.790 & Methyl ethyl ketone & 0,81 & $\mathrm{C}_{4} \mathrm{H}_{8} \mathrm{O}$ & AA \\
\hline 4. & 1.835 & 2-Methyl furan & 0,95 & $\mathrm{C}_{5} \mathrm{H}_{6} \mathrm{O}$ & AAI \\
\hline 5. & 1.881 & 3-Methyl furan & 0,89 & $\mathrm{C}_{5} \mathrm{H}_{6} \mathrm{O}$ & AAI \\
\hline 6. & 2,195 & 3-Methyl butanal & 0,19 & $\mathrm{C}_{5} \mathrm{H}_{10} \mathrm{O}$ & AAI \\
\hline 7. & 2,316 & 2-Methylbutanal & 0,36 & $\mathrm{C}_{5} \mathrm{H}_{10} \mathrm{O}$ & AAI \\
\hline 8. & 2,511 & 1-Pentene-3-ol & 0,84 & $\mathrm{C}_{5} \mathrm{H}_{10} \mathrm{O}$ & AAI \\
\hline 9. & 2,675 & n-Pentanal & 3,40 & $\mathrm{C}_{5} \mathrm{H}_{10} \mathrm{O}$ & AAI \\
\hline 10. & 2,833 & Sorbaldehyde & 1,09 & $\mathrm{C}_{6} \mathrm{H}_{8} \mathrm{O}$ & AAI \\
\hline 11. & 3,324 & 4-Methyl-2-pentanone & 0,25 & $\mathrm{C}_{6} \mathrm{H}_{12} \mathrm{O}$ & AA \\
\hline 12. & 3,823 & (E)-2-Pentenal, & 0,32 & $\mathrm{C}_{5} \mathrm{H}_{8} \mathrm{O}$ & AAI \\
\hline 13. & 3,896 & Amylol & 0,71 & $\mathrm{C}_{5} \mathrm{H}_{12} \mathrm{O}$ & AA \\
\hline 14. & 4,584 & n-Hexanal & 19,35 & $\mathrm{C}_{6} \mathrm{H}_{12} \mathrm{O}$ & AA \\
\hline 15. & 6,072 & E)-2-Hexenal & 0,45 & $\mathrm{C}_{6} \mathrm{H}_{10} \mathrm{O}$ & AA \\
\hline 16. & 6,183 & cis-3-Hexene-1-ol & $\mathrm{C}_{6} \mathrm{H}_{12} \mathrm{O}$ & AA \\
\hline 17. & 6,530 & Z)-2-Hexen-1-ol & 0,18 & $\mathrm{C}_{6} \mathrm{H}_{12} \mathrm{O}$ & AA \\
\hline 18. & 6,633 & n-Hexanol & 1,50 & $\mathrm{C}_{6} \mathrm{H}_{14} \mathrm{O}$ & AA \\
\hline 19. & 7,256 & 2-Heptanone & 0,34 & $\mathrm{C}_{7} \mathrm{H}_{14} \mathrm{O}$ & AA \\
\hline 20. & 7,651 & n-Heptanal & 0,88 & $\mathrm{C}_{7} \mathrm{H}_{14} \mathrm{O}$ & AA \\
\hline 21. & 8,474 & $\alpha-P h e l l a n d r e n e$ & 0,21 & $\mathrm{C}_{10} \mathrm{H}_{16}$ & MH \\
\hline 22. & 8,704 & $\alpha,-$-Pinene & 1,76 & $\mathrm{C}_{10} \mathrm{C}_{16} \mathrm{H}_{6} \mathrm{O}$ & MH \\
\hline 23. & 9,767 & Benzaldehyde & 0,18 & $\mathrm{C}_{10} \mathrm{H}_{16}$ & MH \\
\hline 24. & 10.182 & $\beta .-P h e l l a n d r e n e$ & $\mathrm{C}_{10} \mathrm{H}_{16}$ & MH \\
\hline 25. & 10.330 & $. \beta .-P i n e n e$ & & \\
\hline
\end{tabular}


European Journal of Science and Technology

\begin{tabular}{|c|c|c|c|c|c|}
\hline & R. Time & Bileşenler & $\%$ & Formül & Sinıf \\
\hline 26. & 10.570 & (E)-2-Octen-1-ol, & 0,58 & $\mathrm{C}_{8} \mathrm{H}_{16} \mathrm{O}$ & AAI \\
\hline 27. & 10.722 & 4-Methylhept-6-En-3-One & 0,48 & $\mathrm{C}_{8} \mathrm{H}_{14} \mathrm{O}$ & AAI \\
\hline 28. & 10.870 & .ß.-Myrcene & 0,98 & $\mathrm{C}_{10} \mathrm{H}_{16}$ & MH \\
\hline 29. & 11.414 & n-Octanal & 0,56 & $\mathrm{C}_{8} \mathrm{H}_{16} \mathrm{O}$ & AAI \\
\hline 30. & 11.885 & .a.-Terpinene & 0,68 & $\mathrm{C}_{10} \mathrm{H}_{16}$ & MH \\
\hline 31. & 12.159 & 2,4 Heptadienal & 14,30 & $\mathrm{C}_{7} \mathrm{H}_{10} \mathrm{O}$ & AAI \\
\hline 32. & 12.343 & Limonene & 12,46 & $\mathrm{C}_{10} \mathrm{H}_{16}$ & MH \\
\hline 33. & 12.455 & 1,8-Cineole & 1,13 & $\mathrm{C}_{10} \mathrm{H}_{18} \mathrm{O}$ & $\mathrm{OM}$ \\
\hline 34. & 13.063 & 1,3,7-Octatriene, 3,7-dimethyl- & 1,21 & $\mathrm{C}_{10} \mathrm{H}_{16}$ & $\mathrm{MH}$ \\
\hline 35. & 13.486 & .. -Terpinene & 0,60 & $\mathrm{C}_{10} \mathrm{H}_{16}$ & $\mathrm{MH}$ \\
\hline 36. & 14.640 & Fenchone & 0,56 & $\mathrm{C}_{10} \mathrm{H}_{16} \mathrm{O}$ & $\mathrm{OM}$ \\
\hline 37. & 15.170 & Linalool & 0,36 & $\mathrm{C}_{10} \mathrm{H}_{18} \mathrm{O}$ & $\mathrm{OM}$ \\
\hline 38. & 15.338 & n-Nonanal & 1,62 & $\mathrm{C}_{9} \mathrm{H}_{18} \mathrm{O}$ & AAI \\
\hline 39. & 16.891 & $\begin{array}{l}\text { Bicyclo[2.2.1]heptan-2-one, 1,7,7- } \\
\text { trimethyl-, (1S)- }\end{array}$ & 1,13 & $\mathrm{C}_{10} \mathrm{H}_{16} \mathrm{O}$ & $\mathrm{OM}$ \\
\hline 40. & 22.704 & Dodecane & 0,48 & $\mathrm{C}_{16} \mathrm{H}_{34}$ & $\mathrm{SH}$ \\
\hline 41. & 26.184 & Tetradecane & 0,52 & $\mathrm{C}_{16} \mathrm{H}_{34}$ & SH \\
\hline 42. & 26.420 & Junipene & 0,26 & $\mathrm{C}_{15} \mathrm{H}_{24}$ & $\mathrm{SH}$ \\
\hline \multicolumn{3}{|c|}{ TOPLAM } & 100 & & \\
\hline \multicolumn{3}{|c|}{ Bileşen Sayısı } & 42 & & \\
\hline \multicolumn{3}{|c|}{ AA: Aromatik alkol } & 43,84 & & \\
\hline \multicolumn{3}{|c|}{ AAI: Aromatik aldehit } & 31,26 & & \\
\hline \multicolumn{3}{|c|}{ MH: Monoterpen hidrokarbon } & 20,46 & & \\
\hline \multicolumn{3}{|c|}{ OM: Oksijenli monoterpen } & 3,18 & & \\
\hline \multicolumn{3}{|c|}{ SH: Seskiterpen hidrokarbon } & 1,26 & & \\
\hline
\end{tabular}

\section{Sonuç}

Çalışma sonuçlarına göre Gümüşi ıhlamurun yaprakları 36,66-132,12 mm uzunluk ve 39,23-113,92 mm genişlikte, yaprak sapı ise 20,03-69,34 mm uzunluğunda, simoz çiçek kurulu 4-13 çiçekli, brakteleri ise 40,34-109,5 mm uzunluk ve 5,82-21,83 mm genişlikte olduğu tespit edilmiştir.

SPME (katı faz mikroekstraksiyon yöntemi) analiz yöntemi ile çiçek, brakte ve yapraklarında 42 farklı bileşen belirlenmiş olup, n-Hexanal (\%19,35), (E)-2-Hexenal $(\% 18,45), \quad 2,4$ Heptadienal $(\% 14,30)$ ve Limonene $(\% 12,46)$ oranlarıla ana bileşenler olarak tespit edilmiştir. Uçucu bileşen sınıflarına bakıldığında aromatik alkollerin yüksek oranda olduğu bulunmuştur.

Gümüşi ıhlamur bitkisi gıda, kozmetik ve ilaç endüstrisi gibi farklı sektörlerde kullanılmaktadır. Yaprak, çiçek ve braktelerinden elde edilen uçucu yağıda farklı alanlarda değerlendirilmektedir. Gümüşi hhlamurun kullanım alanlarının artması sonucu her geçen yıl ihracat talebi artmakta ve sadece doğadan toplanmasından dolayı doğal yayılış alanları üzerindeki baskı da artmaktadır. Doğadan usulsüz ve yanlış yöntemlerle toplanan bitkiler biyolojik çeşitliğimizin tahrip edilmesine ve hatta bazı bitkilerin neslinin tükenmesine neden olmaktadır. Bitki çeşitliliğinin azalmaması için bilinçli ve kotalı toplama yöntemleri hakkında bitki toplayıcıların bilinçlenmesi ve türlerin kültüre alınmasının arttırılması sağlanmalıdır. Gümüşi ıhlamurun bilinçsizhasat edilmesi, hasat edilen alanlarda makine kullanılamaması ve ulaşım yetersizliği gibi sorunlardan dolayı üretim kalitesinin düşmesi, gümüşi hhlamur alanlarının tahrip olması ve çiçek brakte veriminde azalmalar olduğu tespit edilmiştir. Son dönemlerde planlı üretim için çalışmalar başlamıştır. Ülkemiz ekonomisine önemli katkı sağlayan ve özellikle kırsal bölge ekonomisinde önemli rol oynayan Odun Dışı Orman Ürünlerinin korunması ve sürdürülebilir şekilde planlanması ve kullanım alanlarının geliştirilmesi açısından bu tarz çalışmalar arttırılmalıdır.

Ihlamurlar tarih boyunca birçok alanda kullanılmıştır. Ihlamurun insan sağllğ 1 üzerinde de olumlu etkileri olduğundan son yıllarda ihlamura olan ilgi daha da artmıştır. Bu nedenlerle de Ihlamurun özelliklerinin daha iyi bilinmesi ve kullanım alanlarının daha iyi ortaya konulması için kapsamlı bilimsel çalışmaların arttırılması ve ekonomik katkısının sürekliliği için bitki ihracatının gelişmesine destek verilmesi çalışma ile önerilmektedir.

\section{Teșekkür}

Bu Çalışma, Tübitak 2209/A Üniversite Öğrencileri Araştırma Projeleri Destek Programı kapsamında desteklenen "Bursa Karacabey'de Doğal Yayılış Yapan Gümüşi Ihlamur (Tilia tomentosa Moench.)'un Bazı Morfolojik Özellikleri ile Yaprak ve Çiçek Uçucu Bileşenlerinin Belirlenmesi" başlıklı projenin sonuçlarını içermektedir. Çalışmamıza verdiği destekten dolayı TÜBITTAK'a teşekkür ederiz. 


\section{Kaynakça}

Akgül, A. ve Ünver, A. (2001). Bitkisel Caylar. Gıda Mühendisliği Dergisi, Selcuk Universitesi Ziraat Fakultesi. 11: 21-24.

Batı Akdeniz Kalkınma Ajansı, (2012). Tıbbi ve Aromatik Bitkiler Sektör Raporu, 2012.

Browicz, K., (1968). Tilia. In: Tutin GT, Heywood VH, Burges NA, More DM, ValentinemDH, Walters SM \& Webb DA, (eds). Flora europaea, rosacea to umbelliferae. Vol. 2, Second edition Cambridge university press.

Başer, H.C., (1998). Tıbbi ve Aromatik Bitkilerin Endüstriyel Kullanımı TAB Bülteni 13-14:19-43.

Başer, K.H.C., (2008). Biological and Phamacological Activities of Carvacrol and Carvacrol Bearing Essantial Oils. Current Farmaceutical Design,14(29), 3106-3120.

Bursa Orman Bölge Müdürlüğü, Plan Proje Şube Müdürlüğü, (2017). Amenajman Plan verileri, 2017.

Davis, P.H., (1967). Flora of Turkey and The East Aegean Islands. Vol: 2, Edinburg University Press.

Demir, D., (2003). Türkiye'de doğal yetişen ihlamur (Tilia L.) taksonlarının orfolojik ve palinolojik özellikleri. İ.Ü. Fen bilimleri, İstanbul, $141 \mathrm{~s}$.

Erdemir, D., A., (1998). At Kestanesi Doğanın Harika İlacı. Uludağ Üniversitesi Tıp Fakültesi. Nobel Kitap Evi, İstanbul.

Fitsiou, I., Tzakou, O., Hancianu, M., Poiata, A. (2011). Volatile Constituents and Antimicrobial Activity of Tilia tomentosa Moench and Tilia cordata Miller Oils. Journal of Essential Oil Research. Vol: 19, 183-185.

Gegiu, A., (2008). Contributions to the knowledge of the composition of essential oils from Tilia tomentosa, Tilia americana and Tilia platyphillos. Lucrări Științifice Universitatea de Științe Agronomice și Medicină Veterinară București. Seria B, Horticultură, No.51, 570-572 ref.5.

Güner, A., Akyıldırım, B., Alkayış, M. F. Çıngay B., Kanoğlu, S.S., Özkan, A.M., Öztekin, M., Tuğ, G.N. (2012). Türkçe bitki adları. Nezahet Gökyiğit Botanik Bahçesi Yayınları Flora Dizisi 1 İstanbul.

Kırbağ, S., Bağcı E., (2000). Picea abies (L.) Karst. ve Picea orientalis (L.) Link Uçucu Yağlarının Antimikrobiyal Aktivitesi Üzerine Bir Araştırma. Journal of Qafqaz University, III, 183-190.

Kıvanç, M., Akgül A., (1986). Antibacterial Activities of Essential Oils from Turkish Spices and Citrus. Flavour and Fragrance Journal, 1,175-179.

Korkusuz, E. E., (2014). Gümüşi Ihlamurun (Tilia tomentosa Moench.) Tohum Özellikleri Üzerine Araştırmalar. İstanbul Üniversitesi, Fen Bilimleri Enstitüsü, Doktora Tezi.

Kubeczka, K.H., (1979). Vorkommen und Analytik Atherischeröle, Georg, Thieme Verlag, Stutgrat.

Pigott, D., (2012). Lime-trees and basswoods: A biological monograph of the genus Tilia.Cambridge university press, New York, 405 pg.

Saatçioglu, F. (1976). Fidanlık Tekniği , . Orm. Fak. Yayın No: 223 , İstanbul.

Şarer, E., (1991). Uçucu Yağların Biyolojik Etkileri ve Tedavide Kullanımları. 9. Bitkisel İlaç Hammaddeleri Toplantısı, Bildiriler Kitapçı̆̆ 1 , Eskişehir.

Tan, A. (1992). Türkiye'de Bitkisel Çeşitlilik ve Bitki Genetik Kaynakları, Anadolu J. of AARI 2: 50-64, MARA.
Toker, M.C., Toker, G., Yılmazer, R., (1997). Ihlamur (Tilia) meyveleri üzerinde morfolojik ve anatomik çalışmalar. Ankara eczacılık fakültesi dergisi, 26 (2) 89-94 pg.

Toker, G., Başer, K. H. C., Kürkçüoğlu, M., Özek, T., (2011). The Composition of Essential Oils from Tilia L. Species Growing in Turkey. Journal of Essential Oil Research, Vol.:11, 369-374.

Tuttu, G., Ursavaş, S., Söyler R., (2017). Ihlamur Çiçeğinin Türkiye'deki Hasat Miktarları ve Etnobotanik Kullanımı, Anadolu Orman Araştırmaları Dergisi, 3 (1) 60-66 Anatolian Journal of Forest Research.Türkiye.

Yaltırık, F., Efe, A., (2000). Dendroloji ders kitabı. İ.Ü. Orman fak. Yayınları no: 465, İstanbul.

URL-1, (2018). Ihlamur (Tilia). Erişim tarihi 15.11.2018. Erişim adresi: http://www.agaclar.net/forum/genis-yaprakliagaclar/438.htm.

Uslu J. (2004). Ihlamur Profil Sektörü, İstanbul Ticaret Odas1 Bilgi İşlem Doküman Odası, 2004. 